DOI: 10.17516/1997-1397-2020-13-3-257-274

УДК 517.9

\title{
Global in Time Results for a Parabolic Equation Solution in Non-rectangular Domains
}

\author{
Louanas Bouzidi* \\ Arezki Kheloufi \\ University of Bejaia \\ Bejaia, Algeria
}

Received 26.11.2019, received in revised form 04.03.2020, accepted 06.04.2020

\begin{abstract}
This article deals with the parabolic equation

$$
\partial_{t} w-c(t) \partial_{x}^{2} w=f \text { in } D, D=\left\{(t, x) \in \mathbb{R}^{2}: t>0, \varphi_{1}(t)<x<\varphi_{2}(t)\right\}
$$

with $\varphi_{i}:[0,+\infty[\rightarrow \mathbb{R}, i=1,2$ and $c:[0,+\infty[\rightarrow \mathbb{R}$ satisfying some conditions and the problem is supplemented with boundary conditions of Dirichlet-Robin type. We study the global regularity problem in a suitable parabolic Sobolev space. We prove in particular that for $f \in L^{2}(D)$ there exists a unique solution $w$ such that $w, \partial_{t} w, \partial^{j} w \in L^{2}(D), j=1,2$. Notice that the case of bounded non-rectangular domains is studied in [9]. The proof is based on energy estimates after transforming the problem in a strip region combined with some interpolation inequality. This work complements the results obtained in [19] in the case of Cauchy-Dirichlet boundary conditions.
\end{abstract}

Keywords: parabolic equations, heat equation, non-rectangular domains, unbounded domains, anisotropic Sobolev spaces.

Citation: L.Bouzidi, A.Kheloufi, Global in time results for a parabolic equation solution in nonrectangular domains, J. Sib. Fed. Univ. Math. Phys., 2020, 13(3), 257-274.

DOI: $10.17516 / 1997-1397-2020-13-3-257-274$

\section{Introduction and statement of the main result}

Let $D$ be an open set of $\mathbb{R}^{2}$ defined by

$$
D:=\left\{(t, x) \in \mathbb{R}^{2}: t>0, \varphi_{1}(t)<x<\varphi_{2}(t)\right\}
$$

where $\varphi_{i} \in C\left(\left[0,+\infty[) \cap C^{1}(0,+\infty), i=1,2\right.\right.$,

$$
\varphi(t):=\varphi_{2}(t)-\varphi_{1}(t)>0 \quad \forall t>0, \text { and } \varphi(0)=0 .
$$

The lateral boundaries of $D$ are defined by

$$
\Gamma_{i}=\left\{\left(t, \varphi_{i}(t)\right) \in \mathbb{R}^{2}: t>0\right\}, i=1,2 .
$$

Let us introduce the following functional space:

$$
\mathcal{H}^{1,2}(D):=\left\{w \in L^{2}(D): \partial_{t} w, \partial_{x} w, \partial_{x}^{2} w \in L^{2}(D)\right\}
$$

\footnotetext{
*bouzidilouanas@yahoo.fr, boumathe@gmail.com

†arezkinet2000@yahoo.fr

(c) Siberian Federal University. All rights reserved
} 
where $L^{2}(D)$ stands for the usual Lebesgue space of square-integrable functions on $D$. The space $\mathcal{H}^{1,2}(D)$ is equipped with the natural norm, that is

$$
\|w\|_{\mathcal{H}^{1,2}(D)}^{2}=\|w\|_{L^{2}(D)}^{2}+\left\|\partial_{t} w\right\|_{L^{2}(D)}^{2}+\sum_{j=1}^{2}\left\|\partial_{x}^{j} w\right\|_{L^{2}(D)}^{2} .
$$

We consider the problem: to find a function $u \in \mathcal{H}^{1,2}(D)$ that satisfies the equation

$$
\partial_{t} u-c(t) \partial_{x}^{2} u=f \text { a.e. on } D
$$

and the boundary conditions

$$
\left.u\right|_{\Gamma_{1}}=\partial_{x} u+\left.\beta_{2} u\right|_{\Gamma_{2}}=0,
$$

where $f \in L^{2}(D)$ and the coefficient $c$ is a continuous real-valued function defined on $[0,+\infty[$, differentiable on $] 0,+\infty[$ and such that

$$
0<\alpha \leqslant c(t) \leqslant \beta
$$

for every $t \in\left[0,+\infty\left[\right.\right.$, where $\alpha$ and $\beta$ are positive constants. Here, the coefficient $\beta_{2}$, in boundary conditions is a real number such that

$$
\beta_{2}>0
$$

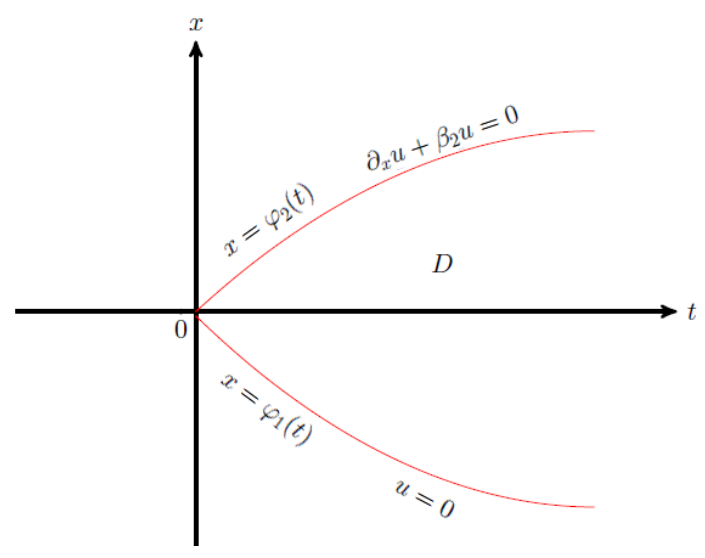

Fig. 1. The unbounded non-rectangular domain D

Problem (1.1)-(1.2) modelizes, for instance, the lateral diffusion of a pollutant in a flow of a river with variable width. Note that the Robin type condition

$$
\partial_{x} u+\left.\beta_{2} u\right|_{\Gamma_{2}}=0
$$

means for instance, that the flux of diffusion of the pollutant is proportional to its propagation along the wide of the river. The most interesting points of the parabolic problem studied here is the unboundedness of $D$ with respect to the time variable $t$ and the fact that $D$ shrinks at $t=0(\varphi(0)=0)$ which prevent one using the methods in [13] and [14]. It is well known that there are two main approaches for the study of boundary value problems in such non-regular domains. The analysis can be done in weighted spaces with the weight controlling the behavior of the solutions near the singularity of the boundary of the domain (see, for instance, [10,11] and [12]). Our approach is different. Indeed, the space $\mathcal{H}^{1,2}$ used here has low smoothness but one must add assumptions on the type of the domain $D$, as well as conditions on the coefficients $c$ and $\beta_{2}$, near the singular point 0 and in the neighborhood of $+\infty$. So, our main result is the following: 
Theorem 1.1. Let us assume that

$$
\begin{gathered}
\left|\varphi_{i}^{\prime}(t)\right| \varphi(t) \rightarrow 0 \text { as } t \rightarrow 0^{+}, \quad i=1,2, \\
\left.2 c(t) \beta_{2}-\varphi_{2}^{\prime}(t) \geqslant 0 \text { a.e. } t \in\right] 0,+\infty[, \\
\varphi \text { and } \varphi^{\prime} \text { are uniformly bounded in a neighborhood of }+\infty, \\
c \text { is a decreasing function in }] 0,+\infty[,
\end{gathered}
$$

and one of the following conditions is satisfied

(a) $\varphi$ is increasing in a neighborhood of $+\infty$,

(b) $\exists M>0:\left|\varphi^{\prime}\right| \varphi \leqslant M c(t)$.

Then Problem (1.1), (1.2) admits a unique solution $u \in \mathcal{H}^{1,2}(D)$.

The case where $D$ is bounded (with $c(t)=1$ ) is studied in [9]. The case where $\beta_{2}=\infty$ corresponding to Cauchy-Dirichlet boundary conditions is studied in [19]. Whereas secondorder parabolic equations in bounded non-cylindrical domains are well studied (see for instance $[2,5,7,15-18]$ and the references therein), the literature concerning unbounded non-cylindrical domains does not seem to be very rich. The regularity of the heat equation solution in a nonsmooth and unbounded domain (in the $x$ direction) is obtained in $[3,6,8]$ and [4].

In the next sections, we prove Theorem 1.1 in four steps:

(1) case of a bounded domain which can be transformed into a rectangle;

(2) case of an unbounded domain which can be transformed into a half strip;

(3) case of a small in time bounded triangular domain;

(4) finally, we use the previous steps and a trace result to complete the proof of Theorem 1.1.

\section{The case of a bounded domain which can be transformed into a rectangle}

Let $T$ be an arbitrary positive number. Denote by

$$
D_{1}:=\left\{(t, x) \in \mathbb{R}^{2}: 0<t<T ; \varphi_{1}(t)<x<\varphi_{2}(t)\right\}
$$

with $\varphi(t)>0$ for all $t \in[0, T]$ and consider the following problem:

$$
\left\{\begin{array}{l}
\partial_{t} u-c(t) \partial_{x}^{2} u=f_{1} \text { a.e. on } D_{1}, \\
\left.u\right|_{\Gamma_{1}}=\left.u\right|_{\Gamma_{0}}=0 \\
\partial_{x} u+\left.\beta_{2} u\right|_{\Gamma_{2}}=0
\end{array}\right.
$$

where $f_{1} \in L^{2}\left(D_{1}\right)$ and $\Gamma_{0}$ is the part of $\partial D_{1}$ where $t=0$.

Let us denote the inner product in $L^{2}\left(D_{1}\right)$ by $\langle.,$.$\rangle . Then, the uniqueness of the solutions$ may be obtained by developing the inner product

$$
\left\langle\partial_{t} u-c(t) \partial_{x}^{2} u, u\right\rangle
$$

Indeed, Let us consider $u \in \mathcal{H}^{1,2}\left(D_{1}\right)$ a solution of Problem (2.1) with a null right-hand side term. So,

$$
\partial_{t} u-c(t) \partial_{x}^{2} u=0 \text { in } D_{1}
$$




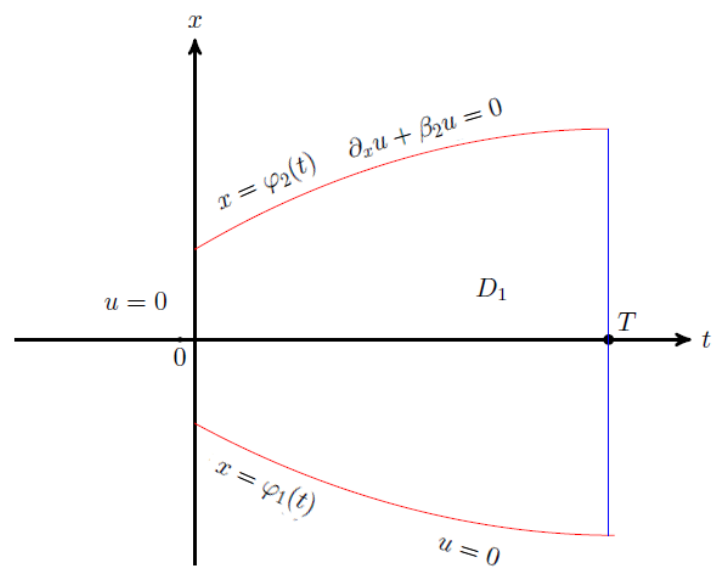

Fig. 2. The bounded domain $D_{1}$

In addition $u$ fulfils the boundary conditions

$$
\left.u\right|_{\Gamma_{0}}=\left.u\right|_{\Gamma_{1}}=\partial_{x} u+\left.\beta_{2} u\right|_{\Gamma_{2}}=0 .
$$

Using Green formula, we have

$$
\int_{D_{1}}\left(\partial_{t} u-c(t) \partial_{x}^{2} u\right) u d t d x=\int_{\partial D_{1}}\left(\frac{1}{2}|u|^{2} \nu_{t}-c(t) \partial_{x} u \cdot u \nu_{x}\right) d \sigma+\int_{D_{1}} c(t)\left(\left|\partial_{x} u\right|^{2}\right) d t d x
$$

where $\nu_{t}, \nu_{x}$ are the components of the unit outward normal vector at $\partial D_{1}$. We shall rewrite the boundary integral making use of the boundary conditions. On the part of the boundary of $D_{1}$ where $t=0$, we have $u=0$. Accordingly the corresponding boundary integral vanishes. On the part of the boundary of $D_{1}$ where $t=T$, we have $\nu_{x}=0$ and $\nu_{t}=1$. Accordingly the corresponding boundary integral

$$
\frac{1}{2} \int_{\varphi_{1}(T)}^{\varphi_{2}(T)}|u|^{2}(T, x) d x
$$

is nonnegative. On the parts of the boundary where $x=\varphi_{i}(t), i=1,2$, we have

$$
\nu_{x}=\frac{(-1)^{i}}{\sqrt{1+\left(\varphi_{i}^{\prime}\right)^{2}(t)}}, \quad \nu_{t}=\frac{(-1)^{i+1} \varphi_{i}^{\prime}(t)}{\sqrt{1+\left(\varphi_{i}^{\prime}\right)^{2}(t)}}
$$

and

$$
u\left(t, \varphi_{1}(t)\right)=\partial_{x} u\left(t, \varphi_{2}(t)\right)+\beta_{2} u\left(t, \varphi_{2}(t)\right)=0 .
$$

Consequently, the corresponding integral is

$$
\int_{0}^{T} \frac{1}{2}\left(2 c(t) \beta_{2}-\varphi_{2}^{\prime}(t)\right) u^{2}\left(t, \varphi_{2}(t)\right) d t
$$

Then, we obtain

$$
\begin{aligned}
\int_{D_{1}}\left(\partial_{t} u-c(t) \partial_{x}^{2} u\right) u d t d x= & \frac{1}{2} \int_{0}^{T}\left(2 c(t) \beta_{2}-\varphi_{2}^{\prime}(t)\right) u^{2}\left(t, \varphi_{2}(t)\right) d t+ \\
& +\frac{1}{2} \int_{\varphi_{1}(T)}^{\varphi_{2}(T)}|u|^{2}(T, x) d x+\int_{D_{1}} c(t)\left(\left|\partial_{x} u\right|^{2}\right) d t d x
\end{aligned}
$$


Consequently using the fact that $u$ is the solution yields

$$
\int_{D_{1}} c(t)\left(\left|\partial_{x} u\right|^{2}\right) d t d x=0
$$

because thanks to the condition (1.4) and to the fact that $c(t)>0$ for every $t \in[0,+\infty[$, we have

$$
\frac{1}{2} \int_{0}^{T}\left(2 c(t) \beta_{2}-\varphi_{2}^{\prime}(t)\right) u^{2}\left(t, \varphi_{2}(t)\right) d t+\frac{1}{2} \int_{\varphi_{1}(T)}^{\varphi_{2}(T)}|u|^{2}(T, x) d x+\int_{D_{1}} c(t)\left(\left|\partial_{x} u\right|^{2}\right) d t d x \geqslant 0
$$

This implies that $\left|\partial_{x} u\right|^{2}=0$ and consequently $\partial_{x}^{2} u=0$. Then, the hypothesis $\partial_{t} u-c(t) \partial_{x}^{2} u=0$ gives $\partial_{t} u=0$. Thus, $u$ is a constant. The boundary conditions and the fact that $\beta_{2} \neq 0$, imply that $u=0$ in $D_{1}$. This proves the uniqueness of the solution of Problem (2.1).

Now, let us look at the existence of solutions for Problem $(2.1)$. The change of variables $(t, x)$ to $\left(t, \frac{x-\varphi_{1}(t)}{\varphi(t)}\right)$ transforms $D_{1}$ into the rectangle $\left.Q=\right] 0, T[\times] 0,1[$ and Problem $(2.1)$ becomes the following:

$$
\left\{\begin{array}{l}
\partial_{t} u+a(t, x) \partial_{x} u-\frac{c(t)}{\varphi^{2}(t)} \partial_{x}^{2} u=f_{1} \text { a.e. on } Q \\
\left.u\right|_{t=0}=\left.u\right|_{x=0}=0 \\
\partial_{x} u+\left.\beta_{2} \varphi(t) u\right|_{x=1}=0
\end{array}\right.
$$

where $f_{1} \in L^{2}(Q)$ and $a(t, x)=-\frac{x \varphi^{\prime}(t)+\varphi_{1}^{\prime}(t)}{\varphi(t)}$. Observe that the coefficient $a$ is bounded. So, the operator

$$
a(t, x) \partial_{x}: \mathcal{H}^{1,2}(Q) \longrightarrow L^{2}(Q)
$$

is compact. Hence, it is sufficient to study the following problem:

$$
\left\{\begin{array}{l}
\partial_{t} u-\frac{c(t)}{\varphi^{2}(t)} \partial_{x}^{2} u=f_{1} \text { a.e. on } Q \\
\left.u\right|_{t=0}=\left.u\right|_{x=0}=0 \\
\partial_{x} u+\left.\beta_{2} \varphi(t) u\right|_{x=1}=0
\end{array}\right.
$$

where $f_{1} \in L^{2}(Q)$. It is clear that Problem (2.2) admits a (unique) solution $u \in \mathcal{H}^{1,2}(Q)$ because the coefficient $\frac{c(t)}{\varphi^{2}(t)}$ satisfies the "uniform parabolicity" condition (see, for example [1]). On other hand, it is easy to verify that the aforementioned change of variable conserves the spaces $L^{2}$ and $\mathcal{H}^{1,2}$. Consequently, we have proved the following theorem:

Theorem 2.1. Problem (2.1) admits a (unique) solution $u \in \mathcal{H}^{1,2}\left(D_{1}\right)$.

\section{The case of an unbounded domain which can be transformed into a half strip}

In this case, we set

$$
D_{2}:=\left\{(t, x) \in \mathbb{R}^{2}: t>0 ; \varphi_{1}(t)<x<\varphi_{2}(t)\right\}
$$


with $\varphi(0)>0$ and consider the following problem:

$$
\left\{\begin{array}{l}
\partial_{t} u-c(t) \partial_{x}^{2} u=f_{1} \text { a.e. on } D_{2}, \\
\left.u\right|_{\Gamma_{1}}=\left.u\right|_{\Gamma_{0}}=0 \\
\partial_{x} u+\left.\beta_{2} u\right|_{\Gamma_{2}}=0
\end{array}\right.
$$

where $f_{1} \in L^{2}\left(D_{2}\right)$, and $\Gamma_{0}$ is the part of $\partial D_{2}$ where $t=0$.

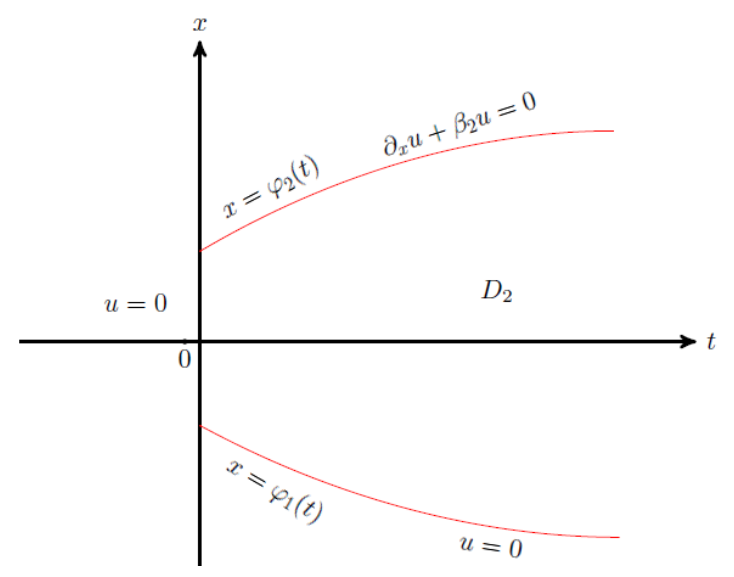

Fig. 3. The unbounded domain $D_{2}$

The change of variables indicated in the previous section transforms $D_{2}$ into the half strip $P=] 0,+\infty[\times] 0,1[$. So Problem (3.1) can be written as follows:

$$
\left\{\begin{array}{l}
\partial_{t} u+a(t, x) \partial_{x} u-\frac{c(t)}{\varphi^{2}(t)} \partial_{x}^{2} u=f_{1} \text { a.e. on } P, \\
\left.u\right|_{t=0}=\left.u\right|_{x=0}=0, \\
\partial_{x} u+\left.\beta_{2} \varphi(t) u\right|_{x=1}=0,
\end{array}\right.
$$

where $f_{1} \in L^{2}(P)$ and the coefficients $a$ is that defined in Section 2 .

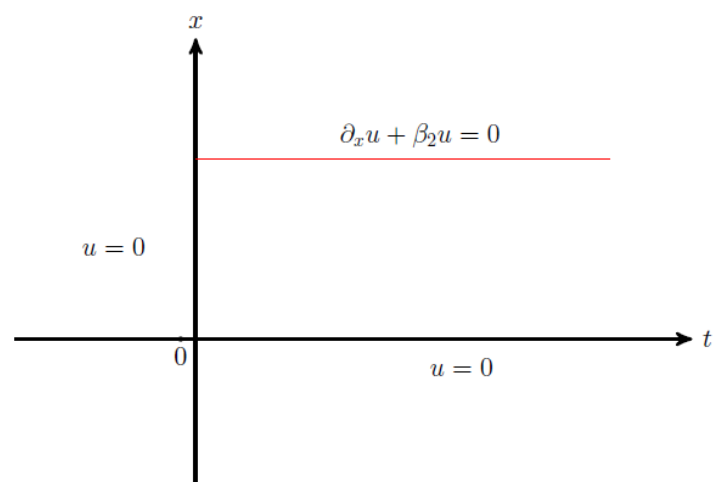

Fig. 4. The half strip $\mathrm{P}$

Let $f_{1}^{(n)}$ be the restriction $\left.f_{1}\right|_{] 0, n[\times] 0,1[}$, for all $n \in \mathbb{N}^{*}$. Then, Theorem 2.1 shows that for all 
$n \in \mathbb{N}^{*}$, there exists a function $u_{n} \in \mathcal{H}^{1,2}\left(P_{n}\right)$ which solves the problem

$$
\left\{\begin{array}{l}
\partial_{t} u_{n}+a(t, x) \partial_{x} u_{n}-\frac{c(t)}{\varphi^{2}(t)} \partial_{x}^{2} u_{n}=f_{1}^{(n)} \text { a.e. on } P_{n}, \\
\left.u_{n}\right|_{t=0}=\left.u_{n}\right|_{x=0}=0 \\
\partial_{x} u_{n}+\left.\beta_{2} \varphi(t) u_{n}\right|_{x=1}=0
\end{array}\right.
$$

where $f_{1}^{(n)} \in L^{2}\left(P_{n}\right)$, and $\left.P_{n}=\right] 0, n[\times] 0,1[$.

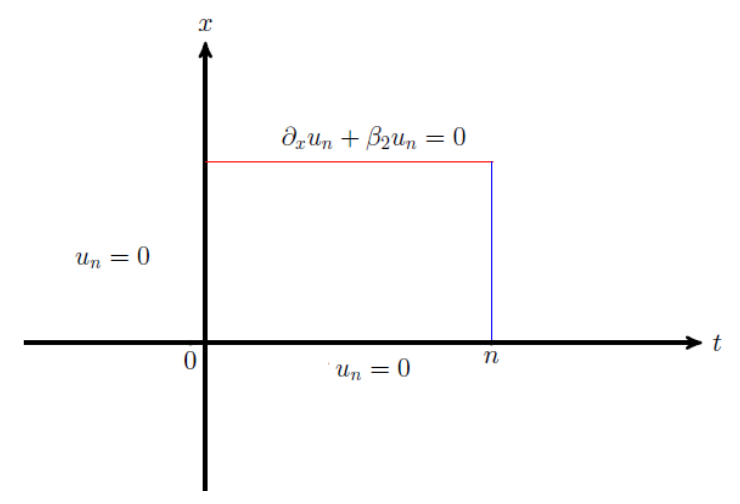

Fig. 5. The truncated half strip Pn

Now, let us prove an "energy" type estimate for the solutions $u_{n}$ which will allow us to solve Problem (3.2) and then equivalently Problem (3.1).

Proposition 3.1. There exists a constant $K>0$ independent of $n$ such that

$$
\left\|u_{n}\right\|_{\mathcal{H}^{1,2}\left(P_{n}\right)}^{2} \leqslant K\left\|f_{1}^{(n)}\right\|_{L^{2}\left(P_{n}\right)}^{2} \leqslant K\left\|f_{1}\right\|_{L^{2}(P)}^{2} .
$$

In order to prove Proposition 3.1, we need the following result:

Lemma 3.1. There exists a constant $K$ independent of $n$ such that

$$
\left\|u_{n}\right\|_{L^{2}\left(P_{n}\right)}^{2} \leqslant K\left\|\partial_{x} u_{n}\right\|_{L^{2}\left(P_{n}\right)}^{2} \leqslant K\left\|f_{1}\right\|_{L^{2}(P)}^{2} .
$$

Proof. The Poincaré inequality gives $\left\|u_{n}\right\|_{L^{2}\left(P_{n}\right)} \leqslant K\left\|\partial_{x} u_{n}\right\|_{L^{2}\left(P_{n}\right)}$. Now, we estimate the inner product $\left\langle f_{1}^{(n)}, u_{n}\right\rangle$.

Estimation of $\left\langle f_{1}^{(n)}, u_{n}\right\rangle$ :

$$
\begin{aligned}
\left\langle f_{1}^{(n)}, u_{n}\right\rangle= & \int_{P_{n}} u_{n} \partial_{t} u_{n} d t d x+\int_{P_{n}} a(t, x) u_{n} \partial_{x} u_{n} d t d x-\int_{P_{n}} \frac{c(t)}{\varphi^{2}(t)} u_{n} \partial_{x}^{2} u_{n} d t d x= \\
= & \int_{\partial P_{n}}\left[\frac{1}{2}\left|u_{n}\right|^{2} \nu_{t}+a(t, x) \frac{1}{2}\left|u_{n}\right|^{2} \nu_{x}-\frac{c(t)}{\varphi^{2}(t)} \partial_{x} u_{n} \cdot u_{n} \nu_{x}\right] d \sigma+ \\
& +\int_{P_{n}} \frac{c(t)}{\varphi^{2}(t)}\left(\partial_{x} u_{n}\right)^{2} d t d x-\frac{1}{2} \int_{P_{n}} \partial_{x} a(t, x)\left|u_{n}\right|^{2} d t d x,
\end{aligned}
$$

where $\nu_{t}, \nu_{x}$ are the components of the unit outward normal vector at the boundary of $P_{n}$. We shall rewrite the boundary integral making use of the boundary conditions. On the part of the boundary of $P_{n}$ where $t=0$, we have $u_{n}=0$ and consequently the corresponding boundary 
integral vanishes. On the part of the boundary where $t=n$, we have $\nu_{x}=0$ and $\nu_{t}=1$. Accordingly the corresponding boundary integral is the following:

$$
\int_{0}^{1} \frac{1}{2}\left(u_{n}\right)^{2}(n, x) d x
$$

On the part of the boundary where $x=0$, we have $\nu_{x}=-1, \nu_{t}=0$ and $u_{n}(t, 0)=0$. Consequently, the corresponding integral vanishes. On the part of the boundary where $x=1$, we have $\nu_{x}=1, \nu_{t}=0$ and

$$
\partial_{x} u_{n}(t, 1)+\beta_{2} \varphi(t) u_{n}(t, 1)=0 .
$$

Consequently, the corresponding integral is

$$
\int_{0}^{n} \frac{\left(2 c(t) \beta_{2}-\varphi_{2}^{\prime}(t)\right)}{2 \varphi(t)}\left(u_{n}\right)^{2}(t, 1) d t
$$

Finally,

$$
\begin{aligned}
\left\langle f_{1}^{(n)}, u_{n}\right\rangle= & \int_{\varphi_{1}(n)}^{\varphi_{2}(n)} \frac{1}{2}\left(u_{n}\right)^{2}(n, x) d x+\int_{0}^{n} \frac{\left(2 c(t) \beta_{2}-\varphi_{2}^{\prime}(t)\right)}{2 \varphi(t)}\left(u_{n}\right)^{2}(t, 1) d t+ \\
& +\int_{P_{n}} \frac{c(t)}{\varphi^{2}(t)}\left(\partial_{x} u_{n}\right)^{2} d t d x+\frac{1}{2} \int_{P_{n}} \frac{\varphi^{\prime}(t)}{\varphi(t)}\left|u_{n}\right|^{2} d t d x .
\end{aligned}
$$

Thanks to the condition (1.4) and since the function $\varphi$ increases, we obtain

$$
\left\langle f_{1}^{(n)}, u_{n}\right\rangle \geqslant \int_{P_{n}} \frac{c(t)}{\varphi^{2}(t)}\left(\partial_{x} u_{n}\right)^{2} d t d x \geqslant C\left\|\partial_{x} u_{n}\right\|_{L^{2}\left(P_{n}\right)}^{2} .
$$

Hence, for all $\epsilon>0$,

$$
\begin{aligned}
\left\|\partial_{x} u_{n}\right\|_{L^{2}\left(P_{n}\right)}^{2} & \leqslant \frac{1}{C}\left\|u_{n}\right\|_{L^{2}\left(P_{n}\right)}\left\|f_{1}^{(n)}\right\|_{L^{2}\left(P_{n}\right)} \leqslant \\
& \leqslant \frac{1}{C \epsilon}\left\|f_{1}^{(n)}\right\|_{L^{2}\left(P_{n}\right)}^{2}+\frac{\epsilon}{C}\left\|u_{n}\right\|_{L^{2}\left(P_{n}\right)}^{2} .
\end{aligned}
$$

By using the Poincaré inequality, we obtain

$$
\left(1-\frac{\epsilon}{C}\right)\left\|\partial_{x} u_{n}\right\|_{L^{2}\left(P_{n}\right)}^{2} \leqslant \frac{1}{C \epsilon}\left\|f_{1}^{(n)}\right\|_{L^{2}\left(P_{n}\right)}^{2} .
$$

Choosing $\epsilon$ small enough in the previous inequality, we prove the existence of a constant $K$ such that

$$
\left\|\partial_{x} u_{n}\right\|_{L^{2}\left(P_{n}\right)}^{2} \leqslant K\left\|f_{1}^{(n)}\right\|_{L^{2}\left(P_{n}\right)}^{2} .
$$

Since

$$
\left\|f_{1}^{(n)}\right\|_{L^{2}\left(P_{n}\right)}^{2} \leqslant\left\|f_{1}\right\|_{L^{2}(P)}^{2}
$$

we obtain

$$
\left\|\partial_{x} u_{n}\right\|_{L^{2}\left(P_{n}\right)}^{2} \leqslant K\left\|f_{1}\right\|_{L^{2}(P)}^{2} .
$$

Remark 3.1. Similar computations show that the same result holds true when we substitute the condition that $\varphi$ increases in a neighborhood of $+\infty$ by the following:

$$
\left|\varphi^{\prime}(t)\right| \varphi(t) \leqslant M c(t) .
$$




\section{Proof of Proposition 3.1.}

Let us denote the inner product in $L^{2}\left(P_{n}\right)$ by $\langle.,$.$\rangle , then we have$

$$
\begin{gathered}
\left\|f_{1}^{(n)}\right\|_{L^{2}\left(P_{n}\right)}^{2}=\left\langle\partial_{t} u_{n}+a(t, x) \partial_{x} u_{n}-\frac{c(t)}{\varphi^{2}(t)} \partial_{x}^{2} u_{n}, \partial_{t} u_{n}+a(t, x) \partial_{x} u_{n}-\frac{c(t)}{\varphi^{2}(t)} \partial_{x}^{2} u_{n}\right\rangle= \\
=\left\|\partial_{t} u_{n}\right\|_{L^{2}\left(P_{n}\right)}^{2}+\left\|a \partial_{x} u_{n}\right\|_{L^{2}\left(P_{n}\right)}^{2}+\left\|\frac{c(t)}{\varphi^{2}(t)} \partial_{x}^{2} u_{n}\right\|_{L^{2}\left(P_{n}\right)}^{2}+2 \int_{P_{n}} a \partial_{t} u_{n} \partial_{x} u_{n} d t d x- \\
\quad-2 \int_{P_{n}} a \frac{c(t)}{\varphi^{2}(t)} \partial_{x} u_{n} \partial_{x}^{2} u_{n} d t d x-2 \int_{P_{n}} \frac{c(t)}{\varphi^{2}(t)} \partial_{t} u_{n} \partial_{x}^{2} u_{n} d t d x .
\end{gathered}
$$

Observe that the coefficients $a$ and $\frac{c(t)}{\varphi^{2}(t)}$ are bounded. So, thanks to Lemma 3.1 , for all $\epsilon>0$ we obtain

$$
\begin{aligned}
& \left\|\partial_{t} u_{n}\right\|_{L^{2}\left(P_{n}\right)}^{2}+\left\|\frac{c(t)}{\varphi^{2}(t)} \partial_{x}^{2} u_{n}\right\|_{L^{2}\left(P_{n}\right)}^{2}-2 \int_{P_{n}} \frac{c(t)}{\varphi^{2}(t)} \partial_{t} u_{n} \partial_{x}^{2} u_{n} d t d x \leqslant \\
& \leqslant\left\|f_{1}^{(n)}\right\|_{L^{2}\left(P_{n}\right)}^{2}+\left\|a \partial_{x} u_{n}\right\|_{L^{2}\left(P_{n}\right)}^{2}+2\left\|\partial_{t} u_{n}\right\|_{L^{2}\left(P_{n}\right)}\left\|a \partial_{x} u_{n}\right\|_{L^{2}\left(P_{n}\right)}+ \\
& +2\left\|\partial_{x}^{2} u_{n}\right\|_{L^{2}\left(P_{n}\right)}\left\|a \frac{c(t)}{\varphi^{2}(t)} \partial_{x} u_{n}\right\|_{L^{2}\left(P_{n}\right)} \leqslant \\
& \leqslant\left\|f_{1}^{(n)}\right\|_{L^{2}\left(P_{n}\right)}^{2}+K_{1}\left(1+\frac{2}{\epsilon}\right)\left\|\partial_{x} u_{n}\right\|_{L^{2}\left(P_{n}\right)}^{2}+\epsilon\left\|\partial_{t} u_{n}\right\|_{L^{2}\left(P_{n}\right)}^{2}+\epsilon\left\|\partial_{x}^{2} u_{n}\right\|_{L^{2}\left(P_{n}\right)} \leqslant \\
& \leqslant K_{\epsilon}\left\|f_{1}^{(n)}\right\|_{L^{2}\left(P_{n}\right)}^{2}+\epsilon\left\|\partial_{t} u_{n}\right\|_{L^{2}\left(P_{n}\right)}^{2}+\epsilon\left\|\partial_{x}^{2} u_{n}\right\|_{L^{2}\left(P_{n}\right)}
\end{aligned}
$$

where $K_{\epsilon}$ and $K_{1}$ are constants independent of $n$. Consequently

$$
(1-\epsilon)\left(\left\|\partial_{t} u_{n}\right\|_{L^{2}\left(P_{n}\right)}^{2}+\left\|\partial_{x}^{2} u_{n}\right\|_{L^{2}\left(P_{n}\right)}^{2}\right) \leqslant 2 \int_{P_{n}} \frac{c(t)}{\varphi^{2}(t)} \partial_{t} u_{n} \partial_{x}^{2} u_{n} d t d x+K_{\epsilon}\left\|f_{1}^{(n)}\right\|_{L^{2}\left(P_{n}\right)}^{2} .
$$

Estimation of $2 \int_{P_{n}} \frac{c(t)}{\varphi^{2}(t)} \partial_{t} u_{n} \partial_{x}^{2} u_{n} d t d x$ :

We have

$$
\partial_{t} u_{n} \partial_{x}^{2} u_{n}=\partial_{x}\left(\partial_{t} u_{n} \partial_{x} u_{n}\right)-\frac{1}{2} \partial_{t}\left(\partial_{x} u_{n}\right)^{2}
$$

Then

$$
\begin{array}{r}
2 \int_{P_{n}} \frac{c(t)}{\varphi^{2}(t)} \partial_{t} u_{n} \partial_{x}^{2} u_{n} d t d x=2 \int_{P_{n}} \frac{c(t)}{\varphi^{2}(t)} \partial_{x}\left(\partial_{t} u_{n} \partial_{x} u_{n}\right) d t d x-\int_{P_{n}} \frac{c(t)}{\varphi^{2}(t)} \partial_{t}\left(\partial_{x} u_{n}\right)^{2} d t d x= \\
=\int_{\partial P_{n}} \frac{c(t)}{\varphi^{2}(t)}\left[-\left(\partial_{x} u_{n}\right)^{2} \nu_{t}+2 \partial_{t} u_{n} \partial_{x} u_{n} \nu_{x}\right] d \sigma+\int_{P_{n}}\left(\frac{c(t)}{\varphi^{2}(t)}\right)^{\prime}\left(\partial_{x} u_{n}\right)^{2} d t d x
\end{array}
$$

where $\nu_{t}, \nu_{x}$ are the components of the outward normal vector at the boundary of $P_{n}$. We shall rewrite the boundary integral making use of the boundary conditions. On the part of the boundary of $P_{n}$ where $t=0$, we have $u_{n}=0$ and consequently $\partial_{x} u_{n}=0$. The corresponding boundary integral vanishes. On the part of the boundary where $t=n$, we have $\nu_{x}=0$ and $\nu_{t}=1$. Accordingly the corresponding boundary integral

$$
-\int_{0}^{1} \frac{c(n)}{\varphi^{2}(n)}\left(\partial_{x} u_{n}\right)^{2}(n, x) d x
$$


is negative. On the part of the boundary where $x=0$, we have $\nu_{x}=-1, \nu_{t}=0$ and $u_{n}(t, 0)=0$. Consequently, the corresponding integral vanishes. On the part of the boundary where $x=1$, we have $\nu_{x}=1, \nu_{t}=0$ and

$$
\partial_{x} u_{n}(t, 1)+\beta_{2} \varphi(t) u_{n}(t, 1)=0 .
$$

Consequently, the corresponding integral is

$$
\left.\int_{0}^{n} \frac{-2 \beta_{2} c(t)}{\varphi(t)}\right) \partial_{t} u_{n}(t, 1) u_{n}(t, 1) d t=\frac{-\beta_{2} c(n)}{\varphi(n)} u_{n}^{2}(n, 1)+\int_{0}^{n} \beta_{2}\left(\frac{c(t)}{\varphi(t)}\right)^{\prime} u_{n}^{2}(t, 1) d t,
$$

which is negative thanks to the condition (1.6) and to the fact that $\beta_{2}>0$. Finally,

$$
\begin{aligned}
2 \int_{P_{n}} \frac{c(t)}{\varphi^{2}(t)} \partial_{t} u_{n} \partial_{x}^{2} u_{n} d t d x= & -\int_{0}^{1} \frac{c(n)}{\varphi^{2}(n)}\left(\partial_{x} u_{n}\right)^{2}(n, x) d x-\frac{\beta_{2} c(n)}{\varphi(n)} u_{n}^{2}(n, 1)+ \\
& +\int_{0}^{n} \beta_{2}\left(\frac{c(t)}{\varphi(t)}\right)^{\prime} u_{n}^{2}(t, 1) d t+\int_{P_{n}}\left(\frac{c(t)}{\varphi^{2}(t)}\right)^{\prime}\left(\partial_{x} u_{n}\right)^{2} d t d x
\end{aligned}
$$

Note that the functions $\frac{c(t)}{\varphi^{2}(t)}$ and $\left(\frac{c(t)}{\varphi^{2}(t)}\right)^{\prime}$ are bounded. So, by using Lemma 3.1 , we deduce

$$
\begin{aligned}
2 \int_{P_{n}} \frac{c(t)}{\varphi^{2}(t)} \partial_{t} u_{n} \partial_{x}^{2} u_{n} d t d x & \leqslant \int_{P_{n}}\left(\frac{c(t)}{\varphi^{2}(t)}\right)^{\prime}\left(\partial_{x} u_{n}\right)^{2} d t d x \leqslant \\
& \leqslant K_{2}\left\|\partial_{x} u_{n}\right\|_{L^{2}\left(P_{n}\right)}^{2} \leqslant \\
& \leqslant K_{3}\left\|f_{1}\right\|_{L^{2}(P)}^{2}
\end{aligned}
$$

where $K_{2}$ and $K_{3}$ are constants independent of $n$. Consequently, Choosing $\epsilon=\frac{1}{2}$ in the relationship (3.4), we obtain

$$
\left\|\partial_{t} u_{n}\right\|_{L^{2}\left(P_{n}\right)}^{2}+\left\|\partial_{x}^{2} u_{n}\right\|_{L^{2}\left(P_{n}\right)}^{2} \leqslant K\left\|f_{1}\right\|_{L^{2}(P)}^{2} .
$$

Consequently, making use of Lemma 3.1 and the previous estimate, then, there exists a constant $K>0$, independent of $n$ satisfying

$$
\left\|u_{n}\right\|_{\mathcal{H}^{1,2}\left(P_{n}\right)}^{2} \leqslant K\left\|f_{1}\right\|_{L^{2}(P)}^{2} .
$$

This ends the proof of Proposition 3.1.

Remark 3.2. We obtain the solution u of Problem (3.1) by letting $n$ go to infinity in the previous proposition. The uniqueness can be proved as in Theorem 2.1.

Finally, we have proved the following Theorem:

Theorem 3.1. Problem (3.1) admits a (unique) solution $u \in \mathcal{H}^{1,2}\left(D_{2}\right)$.

\section{The case of a small in time bounded triangular domain}

Let $T$ be a small enough positive real number. We set

$$
D_{3}:=\left\{(t, x) \in \mathbb{R}^{2}: 0<t<T ; \varphi_{1}(t)<x<\varphi_{2}(t)\right\}
$$

with $\varphi(0)=0$ and consider the following problem:

$$
\left\{\begin{array}{l}
\partial_{t} u-c(t) \partial_{x}^{2} u=f_{1} \text { a.e. on } D_{3} \\
\left.u\right|_{\Gamma_{1}}=0 \\
\partial_{x} u+\left.\beta_{2} u\right|_{\Gamma_{2}}=0
\end{array}\right.
$$


where $f_{1} \in L^{2}\left(D_{3}\right)$. Set

$$
Q_{n}=\left\{(t, x) \in D_{3}: \frac{1}{n}<t<T\right\}, n \in \mathbb{N}^{*} \text { and } \frac{1}{n}<T .
$$

For each $n \in \mathbb{N}^{*}$ such that $\frac{1}{n}<T$, we set $f_{1}^{(n)}=\left.f_{1}\right|_{Q_{n}} \in L^{2}\left(Q_{n}\right)$ and denote by $u_{n} \in \mathcal{H}^{1,2}\left(Q_{n}\right)$ the solution of the following problem:

$$
\left\{\begin{array}{l}
\partial_{t} u_{n}-c(t) \partial_{x}^{2} u_{n}=f_{1} \text { a.e. on } Q_{n}, \\
\left.u_{n}\right|_{t=\frac{1}{n}}=\left.u_{n}\right|_{x=\varphi_{1}(t)}=0, \\
\partial_{x} u_{n}+\left.\beta_{2} u_{n}\right|_{x=\varphi_{2}(t)}=0 .
\end{array}\right.
$$

Such a solution exists by Theorem 2.1 .

Proposition 4.1. There exists a constant $K>0$ independent of $n$ such that

$$
\left\|u_{n}\right\|_{\mathcal{H}^{1,2}\left(Q_{n}\right)}^{2} \leqslant K\left\|f_{1}^{(n)}\right\|_{L^{2}\left(Q_{n}\right)}^{2} \leqslant K\left\|f_{1}\right\|_{L^{2}\left(D_{3}\right)}^{2} .
$$

Remark 4.1. Let $\epsilon>0$ be a real which we will choose small enough. The hypothesis (1.3) implies the existence of a real number $T>0$ small enough such that

$$
\left|\varphi_{i}^{\prime}(t) \varphi(t)\right| \leqslant \epsilon, \text { for all } t \in(0, T), i=1,2 .
$$

In order to prove Proposition 4.1, we need some preliminary results.

Lemma 4.1. There exists a constant $K$ independent of $n$ such that for all $t \in] 0, T[$ :

1) $\left\|u_{n}\right\|_{L^{2}\left(Q_{n}\right)} \leqslant K\left\|\varphi \partial_{x} u_{n}\right\|_{L^{2}\left(Q_{n}\right)}$;

2) $\int_{\varphi_{1}(t)}^{\varphi_{2}(t)} u_{n}^{2}(t, x) d x \leqslant K \varphi^{4} \int_{\varphi_{1}(t)}^{\varphi_{2}(t)}\left(\partial_{x}^{2} u_{n}\right)^{2}(t, x) d x$;

3) $\int_{\varphi_{1}(t)}^{\varphi_{2}(t)}\left(\partial_{x} u_{n}\right)^{2}(t, x) d x \leqslant K \varphi^{2} \int_{\varphi_{1}(t)}^{\varphi_{2}(t)}\left(\partial_{x}^{2} u_{n}\right)^{2}(t, x) d x$

4) $\left\|\partial_{x} u_{n}\right\|_{L^{2}\left(Q_{n}\right)} \leqslant K\left\|f_{1}\right\|_{L^{2}\left(D_{3}\right)}$.

Proof. Inequality (1) is a consequence of the Poincaré inequality.

The following operator is an isomorphism (see, [9])

$$
H_{\gamma}^{2}(0,1) \longrightarrow L^{2}(0,1), u \mapsto u^{\prime \prime},
$$

where,

$$
H_{\gamma}^{2}(0,1)=\left\{u \in H^{2}(0,1): u(0)=0, u^{\prime}(1)+\beta_{2} u(1)=0\right\} .
$$

So, there exists a constant $K>0$ such that

$$
\begin{aligned}
\|u\|_{L^{2}(0,1)} & \leqslant\left\|u^{\prime \prime}\right\|_{L^{2}(0,1)}, \\
\left\|u^{\prime}\right\|_{L^{2}(0,1)} & \leqslant\left\|u^{\prime \prime}\right\|_{L^{2}(0,1)} .
\end{aligned}
$$

The change of variables (for a fixed $t$ )

$$
[0,1] \rightarrow\left[\varphi_{1}(t), \varphi_{2}(t)\right] ; x \longmapsto y=(1-x) \varphi_{1}(t)+x \varphi_{2}(t),
$$


leads to the estimates (2) and (3).

To prove (4), it is sufficient to expand the inner product $\left\langle f_{1}^{(n)}, u_{n}\right\rangle$ and use the inequality (1). Indeed, we deduce for all $\epsilon>0$, (see the proof of uniqueness of solutions in Theorem 2.1)

$$
\begin{aligned}
\int_{Q_{n}} c(t)\left(\partial_{x} u_{n}\right)^{2} d t d x & \leqslant\left|\left\langle f_{1}^{(n)}, u_{n}\right\rangle\right| \leqslant \\
& \leqslant \frac{1}{\epsilon}\left\|f_{1}^{(n)}\right\|_{L^{2}\left(Q_{n}\right)}^{2}+\epsilon\left\|u_{n}\right\|_{L^{2}\left(Q_{n}\right)}^{2} \leqslant \\
& \leqslant \frac{1}{\epsilon}\left\|f_{1}\right\|_{L^{2}\left(D_{3}\right)}^{2}+\epsilon K\left\|\varphi \partial_{x} u_{n}\right\|_{L^{2}\left(Q_{n}\right)}^{2}
\end{aligned}
$$

However, $\varphi$ is bounded and $c>\alpha>0$. Choosing $\epsilon$ small enough yields the desired result.

Proof of Proposition 4.1. Let us denote the inner product in $L^{2}\left(Q_{n}\right)$ by $\langle.,$.$\rangle and set \mathcal{L}:=$ $\partial_{t}-c(t) \partial_{x}^{2}$, then we have

$$
\left\|f_{1}^{(n)}\right\|_{L^{2}\left(Q_{n}\right)}^{2}=\left\langle\mathcal{L} u_{n}, \mathcal{L} u_{n}\right\rangle=\left\|\partial_{t} u_{n}\right\|_{L^{2}\left(Q_{n}\right)}^{2}+\left\|c(t) \partial_{x}^{2} u_{n}\right\|_{L^{2}\left(Q_{n}\right)}^{2}-2\left\langle\partial_{t} u_{n}, c(t) \partial_{x}^{2} u_{n}\right\rangle .
$$

Estimation of $-2\left\langle\partial_{t} u_{n}, c(t) \partial_{x}^{2} u_{n}\right\rangle$ :

We have

$$
\partial_{t} u_{n} \partial_{x}^{2} u_{n}=\partial_{x}\left(\partial_{t} u_{n} \partial_{x} u_{n}\right)-\frac{1}{2} \partial_{t}\left(\partial_{x} u_{n}\right)^{2} .
$$

Then,

$$
\begin{aligned}
-2\left\langle\partial_{t} u_{n}, c(t) \partial_{x}^{2} u_{n}\right\rangle & =-2 \int_{Q_{n}} c(t) \partial_{t} u_{n} \partial_{x}^{2} u_{n} d t d x= \\
& =-2 \int_{Q_{n}} c(t) \partial_{x}\left(\partial_{t} u_{n} \partial_{x} u_{n}\right) d t d x+\int_{Q_{n}} c(t) \partial_{t}\left(\partial_{x} u_{n}\right)^{2} d t d x= \\
& =\int_{\partial Q_{n}} c(t)\left[\left(\partial_{x} u_{n}\right)^{2} \nu_{t}-2 \partial_{t} u_{n} \partial_{x} u_{n} \nu_{x}\right] d \sigma-\int_{Q_{n}} c^{\prime}(t)\left(\partial_{x} u_{n}\right)^{2} d t d x
\end{aligned}
$$

where $\nu_{t}, \nu_{x}$ are the components of the unit outward normal vector at the boundary of $Q_{n}$. We shall rewrite the boundary integral making use of the boundary conditions. On the part of the boundary of $Q_{n}$ where $t=\frac{1}{n}$, we have $u_{n}=0$ and consequently $\partial_{x} u_{n}=0$. The corresponding boundary integral vanishes. On the part of the boundary where $t=T$, we have $\nu_{x}=0$ and $\nu_{t}=1$. Accordingly the corresponding boundary integral

$$
\int_{\varphi_{1}(T)}^{\varphi_{2}(T)} c(T)\left(\partial_{x} u_{n}\right)^{2} d x
$$

is nonnegative. On the parts of the boundary where $x=\varphi_{i}(t), i=1,2$, we have

$$
\nu_{x}=\frac{(-1)^{i}}{\sqrt{1+\left(\varphi_{i}^{\prime}\right)^{2}(t)}}, \nu_{t}=\frac{(-1)^{i+1} \varphi_{i}^{\prime}(t)}{\sqrt{1+\left(\varphi_{i}^{\prime}\right)^{2}(t)}}, u_{n}\left(t, \varphi_{1}(t)\right)=\partial_{x} u_{n}\left(t, \varphi_{2}(t)\right)+\beta_{2} u_{n}\left(t, \varphi_{2}(t)\right)=0 .
$$

Consequently, the corresponding integral is

$$
\begin{aligned}
& -\int_{\frac{1}{n}}^{T} c(t) \varphi_{1}^{\prime}(t)\left[\partial_{x} u_{n}\left(t, \varphi_{1}(t)\right)\right]^{2} d t-2 \int_{\frac{1}{n}}^{T} c(t) \partial_{t} u_{n}\left(t, \varphi_{2}(t)\right) . \partial_{x} u_{n}\left(t, \varphi_{2}(t)\right) d t- \\
& -\int_{\frac{1}{n}}^{T} c(t) \varphi_{2}^{\prime}(t)\left[\partial_{x} u_{n}\left(t, \varphi_{2}(t)\right)\right]^{2} d t .
\end{aligned}
$$


By putting $h(t):=u_{n}\left(t, \varphi_{2}(t)\right), t \in\left[\frac{1}{n}, T\right]$, we obtain

$$
\partial_{t} u_{n}\left(t, \varphi_{2}(t)\right) \partial_{x} u_{n}\left(t, \varphi_{2}(t)\right)=h^{\prime}(t) \partial_{x} u_{n}\left(t, \varphi_{2}(t)\right)-\varphi_{2}^{\prime}(t)\left(\partial_{x} u_{n}\left(t, \varphi_{2}(t)\right)\right)^{2} .
$$

So, by using the boundary conditions, we get

$$
\begin{aligned}
& -2 \int_{\frac{1}{n}}^{T} c(t) \partial_{t} u_{n}\left(t, \varphi_{2}(t)\right) \partial_{x} u_{n}\left(t, \varphi_{2}(t)\right) d t= \\
& \quad=-2 \int_{\frac{1}{n}}^{T} c(t) h^{\prime}(t) \partial_{x} u_{n}\left(t, \varphi_{2}(t)\right) d t+2 \int_{\frac{1}{n}}^{T} c(t) \varphi_{2}^{\prime}(t)\left(\partial_{x} u_{n}\left(t, \varphi_{2}(t)\right)\right)^{2} d t= \\
& \quad=2 \beta_{2} \int_{\frac{1}{n}}^{T} c(t) h^{\prime}(t) h(t) d t+2 \int_{\frac{1}{n}}^{T} c(t) \varphi_{2}^{\prime}(t)\left(\partial_{x} u_{n}\left(t, \varphi_{2}(t)\right)\right)^{2} d t= \\
& \quad=\beta_{2} \int_{\frac{1}{n}}^{T} c(t)\left(h(t)^{2}\right)^{\prime} d t+2 \int_{\frac{1}{n}}^{T} c(t) \varphi_{2}^{\prime}(t)\left(\partial_{x} u_{n}\left(t, \varphi_{2}(t)\right)\right)^{2} d t= \\
& \quad=\beta_{2} c(T)(h(T))^{2}-\beta_{2} \int_{\frac{1}{n}}^{T} c^{\prime}(t) u_{n}^{2}\left(t, \varphi_{2}(t) d t+2 \int_{\frac{1}{n}}^{T} c(t) \varphi_{2}^{\prime}(t)\left(\partial_{x} u_{n}\left(t, \varphi_{2}(t)\right)\right)^{2} d t\right.
\end{aligned}
$$

Observe that, thanks to the condition (1.6) and the fact that $\beta_{2}>0, c(t)>0$, we have

$$
\beta_{2} c(T)(h(T))^{2}-\beta_{2} \int_{\frac{1}{n}}^{T} c^{\prime}(t) u_{n}^{2}\left(t, \varphi_{2}(t) d t \geqslant 0 .\right.
$$

So, by setting

$$
\begin{aligned}
I_{n, 1} & =-\int_{\frac{1}{n}}^{T} c(t) \varphi_{1}^{\prime}(t)\left[\partial_{x} u_{n}\left(t, \varphi_{1}(t)\right)\right]^{2} d t \\
I_{n, 2} & =\int_{\frac{1}{n}}^{T} c(t) \varphi_{2}^{\prime}(t)\left[\partial_{x} u_{n}\left(t, \varphi_{2}(t)\right)\right]^{2} d t
\end{aligned}
$$

we have

$$
-2\left\langle\partial_{t} u_{n}, c(t) \partial_{x}^{2} u_{n}\right\rangle \geqslant-\left|I_{n, 1}\right|-\left|I_{n, 2}\right| .
$$

Estimation of $I_{n, k}, k=1,2$.

Lemma 4.2. There exists a constant $K>0$ independent of $n$ such that

$$
\max \left(\left|I_{n, 1}\right|,\left|I_{n, 2}\right|\right) \leqslant K \epsilon\left\|\partial_{x}^{2} u_{n}\right\|_{L^{2}\left(Q_{n}\right)}^{2} .
$$

Proof. We convert the boundary integral $I_{n, 1}$ into a surface integral by setting

$$
\begin{aligned}
{\left[\partial_{x} u_{n}\left(t, \varphi_{1}(t)\right)\right]^{2} } & =\left.\frac{\varphi_{2}(t)-x}{\varphi_{2}(t)-\varphi_{1}(t)}\left[\partial_{x} u_{n}(t, x)\right]^{2}\right|_{x=\varphi_{1}(t)} ^{x=\varphi_{2}(t)}=\int_{\varphi_{1}(t)}^{\varphi_{2}(t)} \frac{\partial}{\partial x}\left\{\frac{\varphi_{2}(t)-x}{\varphi(t)}\left[\partial_{x} u_{n}(t, x)\right]^{2}\right\} d x= \\
& =2 \int_{\varphi_{1}(t)}^{\varphi_{2}(t)} \frac{\varphi_{2}(t)-x}{\varphi(t)} \partial_{x} v_{n}(t, x) \partial_{x}^{2} u_{n}(t, x) d x-\int_{\varphi_{1}(t)}^{\varphi_{2}(t)} \frac{1}{\varphi(t)}\left[\partial_{x} u_{n}(t, x)\right]^{2} d x .
\end{aligned}
$$


Then, we have

$$
\begin{aligned}
I_{n, 1} & =-\int_{\frac{1}{n}}^{T} c(t) \varphi_{1}^{\prime}(t)\left[\partial_{x} u_{n}\left(t, \varphi_{1}(t)\right)\right]^{2} d t= \\
& =-\int_{Q_{n}} \frac{c(t) \varphi_{1}^{\prime}(t)}{\varphi(t)}\left(\partial_{x} u_{n}\right)^{2} d t d x+2 \int_{Q_{n}} \frac{\varphi_{2}(t)-x}{\varphi(t)} c(t) \varphi_{1}^{\prime}(t)\left(\partial_{x} u_{n}\right)\left(\partial_{x}^{2} u_{n}\right) d t d x .
\end{aligned}
$$

Thanks to Lemma 4.1, we can write

$$
\int_{\varphi_{1}(t)}^{\varphi_{2}(t)}\left[\partial_{x} u_{n}(t, x)\right]^{2} d x \leqslant C[\varphi(t)]^{2} \int_{\varphi_{1}(t)}^{\varphi_{2}(t)}\left[\partial_{x}^{2} u_{n}(t, x)\right]^{2} d x .
$$

Therefore,

$$
\int_{\varphi_{1}(t)}^{\varphi_{2}(t)}\left[\partial_{x} u_{n}(t, x)\right]^{2} \frac{\left|\varphi_{1}^{\prime}\right|}{\varphi} d x \leqslant C\left|\varphi_{1}^{\prime}\right|[\varphi] \int_{\varphi_{1}(t)}^{\varphi_{2}(t)}\left[\partial_{x}^{2} u_{n}(t, x)\right]^{2} d x
$$

consequently,

$$
\left|I_{n, 1}\right| \leqslant C \int_{Q_{n}} c(t)\left|\varphi_{1}^{\prime}\right|[\varphi]\left(\partial_{x}^{2} u_{n}\right)^{2} d t d x+2 \int_{Q_{n}} c(t)\left|\varphi_{1}^{\prime}\right|\left|\partial_{x} u_{n}\right|\left|\partial_{x}^{2} u_{n}\right| d t d x,
$$

since $\left|\frac{\varphi_{2}(t)-x}{\varphi(t)}\right| \leqslant 1$. So, for all $\epsilon>0$, we have

$$
\left|I_{n, 1}\right| \leqslant C \int_{Q_{n}}\left|c(t) \varphi_{1}^{\prime}\right|[\varphi]\left(\partial_{x}^{2} u_{n}\right)^{2} d t d x+\epsilon \int_{Q_{n}} c(t)\left(\partial_{x}^{2} u_{n}\right)^{2} d t d x+\frac{1}{\epsilon} \int_{Q_{n}} c(t)\left(\varphi_{1}^{\prime}\right)^{2}\left(\partial_{x} u_{n}\right)^{2} d t d x
$$

Lemma 4.1 yields

$$
\frac{1}{\epsilon} \int_{Q_{n}} c(t)\left(\varphi_{1}^{\prime}\right)^{2}\left(\partial_{x} u_{n}\right)^{2} d t d x \leqslant C \frac{1}{\epsilon} \int_{Q_{n}} c(t)\left(\varphi_{1}^{\prime}\right)^{2}[\varphi]^{2}\left(\partial_{x}^{2} u_{n}\right)^{2} d t d x
$$

Thus, there exists a constant $M>0$ independent of $n$ such that

$$
\begin{aligned}
\left|I_{n, 1}\right| & \leqslant C \int_{Q_{n}} c(t)\left[\left|\varphi_{1}^{\prime}\right||\varphi|+\frac{1}{\epsilon}\left(\varphi_{1}^{\prime}\right)^{2}|\varphi|^{2}\right]\left(\partial_{x}^{2} u_{n}\right)^{2} d t d x+\epsilon \int_{Q_{n}} c(t)\left(\partial_{x}^{2} u_{n}\right)^{2} d t d x \leqslant \\
& \leqslant M \epsilon \int_{Q_{n}}\left(\partial_{x}^{2} u_{n}\right)^{2} d t d x
\end{aligned}
$$

because $\left|\varphi_{1}^{\prime} \varphi\right| \leqslant \epsilon$. The inequality

$$
\left|I_{n, 2}\right| \leqslant K \epsilon\left\|\partial_{x}^{2} u_{n}\right\|_{L^{2}\left(Q_{n}\right)}^{2},
$$

can be proved by a similar argument.

Now, we can complete the proof of Proposition 4.1. Summing up the estimates (4.4) and those of Lemma 4.2, we then obtain

$$
\begin{aligned}
\left\|f_{1}^{(n)}\right\|_{L^{2}\left(Q_{n}\right)}^{2} & \geqslant\left\|\partial_{t} u_{n}\right\|_{L^{2}\left(Q_{n}\right)}^{2}+\left\|c(t) \partial_{x}^{2} u_{n}\right\|_{L^{2}\left(Q_{n}\right)}^{2}-K_{1} \epsilon\left\|\partial_{x}^{2} u_{n}\right\|_{L^{2}\left(Q_{n}\right)}^{2} \geqslant \\
& \geqslant\left\|\partial_{t} u_{n}\right\|_{L^{2}\left(Q_{n}\right)}^{2}+\left(\alpha^{2}-K_{1} \epsilon\right)\left\|\partial_{x}^{2} u_{n}\right\|_{L^{2}\left(Q_{n}\right)}^{2},
\end{aligned}
$$


where $K_{1}$ is a positive number. Then, it is sufficient to choose $\epsilon$ such that

$$
\alpha^{2}-K_{1} \epsilon>0
$$

to get a constant $K_{0}>0$ independent of $n$ such that

$$
\left\|f_{1}^{(n)}\right\|_{L^{2}\left(Q_{n}\right)}^{2} \geqslant K_{0}\left(\left\|\partial_{t} u_{n}\right\|_{L^{2}\left(Q_{n}\right)}^{2}+\left\|\partial_{x}^{2} u_{n}\right\|_{L^{2}\left(Q_{n}\right)}^{2}\right) .
$$

But

$$
\left\|f_{1}^{(n)}\right\|_{L^{2}\left(Q_{n}\right)} \leqslant\left\|f_{1}\right\|_{L^{2}\left(D_{3}\right)}
$$

then, there exists a constant $K>0$, independent of $n$ satisfying

$$
\left\|\partial_{t} u_{n}\right\|_{L^{2}\left(Q_{n}\right)}^{2}+\left\|\partial_{x}^{2} u_{n}\right\|_{L^{2}\left(Q_{n}\right)}^{2} \leqslant K\left\|f_{1}\right\|_{L^{2}\left(D_{3}\right)}^{2} .
$$

Consequently, making use of Lemma 4.1 and the previous estimates, then, there exists a constant $K>0$, independent of $n$ satisfying.

$$
\left\|u_{n}\right\|_{\mathcal{H}^{1,2}\left(Q_{n}\right)}^{2} \leqslant C\left\|f_{1}\right\|_{L^{2}\left(D_{3}\right)}^{2} .
$$

This ends the proof of Proposition 4.1. Finally, we have proved the following Theorem:

Theorem 4.1. Problem (4.1) admits a (unique) solution $u \in \mathcal{H}^{1,2}\left(D_{3}\right)$.

Proof. We obtain the solution $u$ of Problem (4.1) by letting $n$ go to infinity in the previous proposition. The uniqueness can be proved as in Theorem 2.1.

\section{Back to Problems (1.1)-(1.2) and proof of Theorem 1.1}

The proof of Theorem 1.1 can be obtained by subdividing the domain

$$
D:=\left\{(t, x) \in \mathbb{R}^{2}: t>0, \varphi_{1}(t)<x<\varphi_{2}(t)\right\}
$$

into three open sub-domains $\Omega_{1}, \Omega_{2}$ and $\Omega_{3}$. So, we set $D=\Omega_{1} \cup \Omega_{2} \cup \Omega_{3} \cup \Gamma_{T_{1}} \cup \Gamma_{T_{2}}$ where

$$
\begin{gathered}
\Omega_{1}=\left\{(t, x) \in D: 0<t<T_{1}\right\}, \quad \Omega_{2}=\left\{(t, x) \in D: T_{1}<t<T_{2}\right\}, \quad \Omega_{3}=\left\{(t, x) \in D: t>T_{2}\right\}, \\
\Gamma_{T_{1}}=\left\{\left(T_{1}, x\right) \in \mathbb{R}^{2}: \varphi_{1}\left(T_{1}\right)<x<\varphi_{2}\left(T_{1}\right)\right\} \text { and } \Gamma_{T_{2}}=\left\{\left(T_{2}, x\right) \in \mathbb{R}^{2}: \varphi_{1}\left(T_{2}\right)<x<\varphi_{2}\left(T_{2}\right)\right\}
\end{gathered}
$$

with $T_{1}$ is a small enough positive number and $T_{2}$ is an arbitrary positive number such that $T_{2}>T_{1}$. In the sequel, $f_{1}$ stands for an arbitrary fixed elements of $L^{2}(D)$ and $f_{1}^{(i)}=\left.f_{1}\right|_{\Omega_{i}}$, $i=1,2,3$.

Theorem 4.1 applied to the triangular domain $\Omega_{1}$, shows that there exists a unique solution $w_{1} \in \mathcal{H}^{1,2}\left(\Omega_{1}\right)$ of the problem

$$
\left\{\begin{array}{l}
\partial_{t} w_{1}-c(t) \partial_{x}^{2} w_{1}=f_{1}^{(1)} \text { a.e. on } \Omega_{1} \\
\left.w_{1}\right|_{\Gamma_{1,1}}=0 \\
\partial_{x} w_{1}+\left.\beta_{2} w_{1}\right|_{\Gamma_{2,1}}=0
\end{array}\right.
$$

where $f_{1}^{(1)} \in L^{2}\left(\Omega_{1}\right)$ and $\Gamma_{i, 1}$ are the parts of the boundary of $\Omega_{1}$ where $x=\varphi_{i}(t), i=1,2$.

Lemma 5.1. If $w \in \mathcal{H}^{1,2}(] 0, T[\times] 0,1[)$, then $\left.w\right|_{t=0} \in H^{1}\left(\gamma_{0}\right),\left.w\right|_{x=0} \in H^{\frac{3}{4}}\left(\gamma_{1}\right)$ and $\left.w\right|_{x=1} \in$ $H^{\frac{3}{4}}\left(\gamma_{2}\right)$, where $\left.\gamma_{0}=\{0\} \times\right] 0,1\left[, \gamma_{1}=\right] 0, T\left[\times\{0\}\right.$ and $\left.\gamma_{2}=\right] 0, T[\times\{1\}$. 
It is a particular case of Theorem 2.1 ([14, Vol. 2]). The transformation

$$
(t, x) \longmapsto\left(t^{\prime}, x^{\prime}\right)=\left(t, \varphi(t) x+\varphi_{1}(t)\right)
$$

leads to the following lemma:

Lemma 5.2. If $w \in \mathcal{H}^{1,2}\left(\Omega_{2}\right)$, then $\left.w\right|_{\Gamma_{T_{1}}} \in H^{1}\left(\Gamma_{T_{1}}\right),\left.w\right|_{x=\varphi_{1}(t)} \in H^{\frac{3}{4}}\left(\Gamma_{1,2}\right)$ and $\left.w\right|_{x=\varphi_{2}(t)} \in$ $H^{\frac{3}{4}}\left(\Gamma_{2,2}\right)$, where $\Gamma_{i, 2}$ are the parts of the boundary of $\Omega_{2}$ where $x=\varphi_{i}(t), i=1,2$.

Hereafter, we denote the trace $\left.w_{1}\right|_{\Gamma_{T_{1}}}$ by $\psi_{1}$ which is in the Sobolev space $H^{1}\left(\Gamma_{T_{1}}\right)$ because $w_{1} \in \mathcal{H}^{1,2}\left(\Omega_{1}\right)$ (see Lemma 5.2). Now, consider the following problem in $\Omega_{2}$ :

$$
\left\{\begin{array}{l}
\partial_{t} w_{3}-c(t) \partial_{x}^{2} w_{3}=f_{1}^{(2)} \text { a.e. on } \Omega_{2} \\
\left.w_{3}\right|_{\Gamma_{T_{1}}}=\psi_{1} \\
\left.w_{3}\right|_{\Gamma_{1,2}}=0 \\
\partial_{x} w_{3}+\left.\beta_{2} w_{3}\right|_{\Gamma_{2,2}}=0
\end{array}\right.
$$

where $f_{1}^{(2)} \in L^{2}\left(\Omega_{2}\right)$ and $\Gamma_{i, 2}$ are the parts of the boundary of $\Omega_{2}$ where $x=\varphi_{i}(t), i=1,2$. We use the following result, which is a consequence of Theorem 4.3 ([14, Vol.2]), to solve Problem (5.2).

Proposition 5.1. Let $Q$ be the rectangle $] 0, T[\times] 0,1\left[, f_{1}, f_{2} \in L^{2}(Q)\right.$ and $\psi_{1}, \psi_{2} \in H^{1}\left(\gamma_{0}\right)$. Then, the following problem admits a (unique) solution $u \in \mathcal{H}^{1,2}(Q)$ :

$$
\left\{\begin{array}{l}
\partial_{t} u-c(t) \partial_{x}^{2} u=f_{1} \in L^{2}(Q), \\
\left.u\right|_{\gamma_{0}}=\psi_{1} \\
\left.u\right|_{\gamma_{1}}=0 \\
\partial_{x} u+\left.\beta_{2} u\right|_{\gamma_{2}}=0
\end{array}\right.
$$

where $\left.\gamma_{0}=\{0\} \times\right] 0,1\left[, \gamma_{1}=\right] 0, T\left[\times\{0\}\right.$ and $\left.\gamma_{2}=\right] 0, T[\times\{1\}$.

Thanks to the transformation

$$
(t, x) \longmapsto(t, y)=\left(t, \varphi(t) x+\varphi_{1}(t)\right),
$$

we deduce the following result:

Proposition 5.2. Problem (5.2) admits a (unique) solution $w_{3} \in \mathcal{H}^{1,2}\left(\Omega_{2}\right)$.

Hereafter, we denote the trace $\left.w_{3}\right|_{\Gamma_{T_{2}}}$ by $\Phi_{1}$ which is in the Sobolev space $H^{1}\left(\Gamma_{T_{2}}\right)$ because $w_{3} \in \mathcal{H}^{1,2}\left(\Omega_{2}\right)$ (see Lemma 5.2). Now, consider the following problem in $\Omega_{3}$ :

$$
\left\{\begin{array}{l}
\partial_{t} w_{5}-c(t) \partial_{x}^{2} w_{5}=f_{1}^{(3)} \text { a.e. on } \Omega_{3}, \\
\left.w_{5}\right|_{\Gamma_{T_{2}}}=\Phi_{1} \\
\left.w_{5}\right|_{\Gamma_{1,3}}=0 \\
\partial_{x} w_{5}+\left.\beta_{2} w_{5}\right|_{\Gamma_{2,3}}=0
\end{array}\right.
$$

where $f_{1}^{(3)} \in L^{2}\left(\Omega_{3}\right)$ and $\Gamma_{i, 3}$ are the parts of the boundary of $\Omega_{3}$ where $x=\varphi_{i}(t), i=1,2$. By similar arguments like those used previously, we deduce the following result:

Proposition 5.3. Problem (5.3) admits a (unique) solution $w_{5} \in \mathcal{H}^{1,2}\left(\Omega_{3}\right)$.

Finally, the function $u$ defined by

$$
u:=\left\{\begin{array}{l}
w_{1} \text { in } \Omega_{1}, \\
w_{3} \text { in } \Omega_{2}, \\
w_{5} \text { in } \Omega_{3},
\end{array}\right.
$$

is the (unique) solution of Problem (1.1)-(1.2). This ends the proof of Theorem 1.1. 
Remark 5.1. Let us consider the following problem: to find a function $v \in \mathcal{H}^{1,2}(D)$ that satisfies the equation

$$
\partial_{t} v-c(t) \partial_{x}^{2} v=f_{2} \text { a.e. on } D
$$

and the boundary conditions

$$
\left.v\right|_{\Gamma_{2}}=\partial_{x} v+\left.\beta_{1} v\right|_{\Gamma_{1}}=0
$$

where $f_{2} \in L^{2}(D)$ and the coefficient $c$ and the domain $D$ have the same properties as in Problem (1.1),(1.2).

By using the same arguments like those used in solving Problem (1.1), (1.2), we can show that Problem (5.4)-(5.5) admits a (unique) solution $v$ belonging to $\mathcal{H}^{1,2}(D)$, under the assumption

$$
\left.\beta_{1}<0 \text { and } 2 c(t) \beta_{1}-\varphi_{1}^{\prime}(t) \leqslant 0 \text { a.e. } t \in\right] 0,+\infty[.
$$

The authors want to thank the anonymous referee for a careful reading of the manuscript and for his/her helpful suggestions.

\section{References}

[1] Yu.A.Alkhutov, I.T.Mamedov, The first boundary value problem for nondivergence second order parabolic equations with discontinuous coefficients, Mathematics of the USSR-Sbornik, 59(1988), no. 2, 471-495.

[2] Yu.A.Alkhutov, J. Math. Sci. (N. Y.), 142(2007), no. 3, 2021-2032.

DOI: $10.1007 / \mathrm{s} 10958-007-0110-9$

[3] V.N.Aref'ev, L.A.Bagirov, Math. Notes, 64(1998), no. 1-2, 139-153.

DOI: $10.1007 / \mathrm{BF} 02310297$

[4] T.Boudjeriou, A.Kheloufi, J. Sib. Fed. Univ. Math. Phys., 12(2019), no. 3, 355-370.

DOI: 10.17516/1997-1397-2019-12-3-355-370

[5] S.P.Degtyarev, Sbornik: Mathematics, 201(2010), no. 7, 999-1028.

DOI: $10.1070 /$ SM2010v201n07ABEH004100

[6] S.Guesmia, Arch. Math., 101(2013), 293-299. DOI: 10.1007/s00013-013-0555-7

[7] S.Hofmann, J.L.Lewis, The $L^{p}$ Neumann problem for the heat equation in non-cylindrical domains, J. Funct. Anal., 220(2005), no. 1, 1-54.

[8] A.Kheloufi, B.K.Sadallah, Study of a parabolic equation with mixed Dirichlet-Neumann type boundary conditions in unbounded noncylindrical domains, Journal of Advanced Research in Applied Mathematics, $\mathbf{7}(2015)$, no. 4, , 62-77.

[9] A. Kheloufi, On parabolic equations with mixed Dirichlet-Robin type boundary conditions in a non-rectangular domain, Mediterr. J. Math., 13(2016), 1787-1805.

DOI: $10.1007 / \mathrm{s} 00009-015-0616-1$

[10] V.A.Kondrat'ev, Boundary problems for parabolic equations in closed regions, Am. Math. Soc. Providence. R I., 1966, 450-504.

[11] V.A.Kozlov, V.G.Maz'ya, On singularities of a solution to the first boundary value problem for the heat equation in domains with conical points, I, Soviet Math. (Iz. VUZ, no. 2), 31(1987), 61-74. 
[12] V.A.Kozlov, V.G.Maz'ya, Singularities of solutions of the first boundary value problem for the heat equation in domains with conical points. II, Soviet Math. (Iz. VUZ, no. 3), 31(1987), 61-74.

[13] O.A.Ladyzhenskaya, V.A.Solonnikov, N.N.Ural'tseva, Linear and Quasilinear Equations of Parabolic Type, (Russian), Translated from the Russian by S. Smith. Translations of Mathematical Monographs, Vol. 23 American Mathematical Society, Providence, R.I., 1968.

[14] J.L.Lions, E.Magenes, Problèmes aux limites non homogènes et applications, 1,2, Dunod, Paris, 1968.

[15] F.Paronetto, An existence result for evolution equations in non-cylindrical domains, Nonlinear Differ. Equ. Appl., 20(2013), 1723-1740. DOI: 10.1007/s00030-013-0227-0

[16] A.I.Nazarov, J. of Math. Sci., 106(2001), no. 3, 2989-3014. DOI: 10.1023/A:1011319521775

[17] M.A.Ragusa, Cauchy-Dirichlet problem associated to divergence form parabolic equations, Communications in Contemporary Mathematics, 6(2004), no. 3, , 377-393.

[18] B.-K.Sadallah, Etude d'un problème $2 m$-parabolique dans des domaines plan non rectangulaires, Boll. Un. Mat. Ital., 2-B(1983), no. 5, 51-112.

[19] B.K.Sadallah, Regularity of a parabolic equation solution in a non-smooth and unbounded domain, J. Aust. Math. Soc., 84(2008), no. 2, 265-276.

\title{
Глобальные во времени результаты для решения параболического уравнения в непрямоугольных областях
}

\author{
Луанас Бузиди \\ Арезки Хелоуфи \\ Университет Беджая \\ Беджая, Алжир
}

\begin{abstract}
Аннотация. В этой статье рассматривается параболическое уравнение

$$
\partial_{t} w-c(t) \partial_{x}^{2} w=f \text { in } D, D=\left\{(t, x) \in \mathbb{R}^{2}: t>0, \varphi_{1}(t)<x<\varphi_{2}(t)\right\},
$$

где $\varphi_{i}:[0,+\infty[\rightarrow \mathbb{R}, i=1,2$ и $c:[0,+\infty[\rightarrow \mathbb{R}$, удовлетворяя некоторым условиям, задача дополняется граничными условиями типа Дирихле-Робина. Мы изучаем проблему глобальной регулярности в подходящем параболическом пространстве Соболева. В частности, докажем, что для $f \in L^{2}(D)$ существует единственное решение $w$ такое, что $w, \partial_{t} w, \partial^{j} w \in L^{2}(D), j=1,2$. Обратите внимание, что случай ограниченных непрямоугольных областей изучается в [9]. Доказательство основано на оценках энергии после преобразования задачи в полосовой области в сочетании с некоторым интерполяционным неравенством. Эта работа дополняет результаты, полученные в [19] в случае граничных условий Коши-Дирихле.
\end{abstract}

Ключевые слова: параболические уравнения, уравнение теплопроводности, непрямоугольные области, неограниченные области, анизотропные пространства Соболева. 